\title{
How Social Pensions and Income Contributes to Successful Ageing? A Mixed Method Study
}

\author{
Nicamil Sanchez $\mathbf{K}^{*}$ \\ Philippines
}

ISSN: 2578-0093

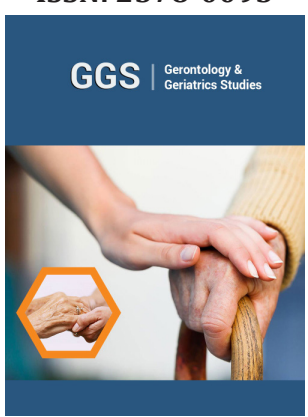

${ }^{*}$ Corresponding author: Nicamil Sanchez K, Philippines

Submission: 齿 February 22, 2019

Published: 眥March 20, 2019

Volume 4 - Issue 4

How to cite this article: Nicamil Sanchez K. How Social Pensions and Income Contributes to Successful Ageing? A Mixed Method Study. Gerontol \& Geriatric stud.4(4). GGS.000594.2019.

DOI: 10.31031/GGS.2019.04.000594

Copyright@ Nicamil Sanchez K, This article is distributed under the terms of the Creative Commons Attribution 4.0 International License, which permits unrestricted use and redistribution provided that the original author and source are credited.

\begin{abstract}
Rationale

Ageing of global populations is not only a reality in developed countries; it is also becoming a reality in developing countries like the Philippines. Developing countries like the Philippines will need to prepare for the challenges, and also as well as capitalise on the opportunities, brought about by the increasing numbers of older persons. Income and social pensions are important social safety net to address poverty and hunger in old age. Social pension is a universal benefit in developed countries and is now receiving increased attention in developing countries which is associated with income in old age. In the Philippines, social pensions were implemented for indigent senior citizens which provides monthly stipend to augment the daily subsistence and other medical needs of senior citizens. This study found that social pensions may not be associated with successful ageing, since a majority of the respondents who received social pensions did not attain the three dimensions of successful ageing.
\end{abstract}

More so, this study suggest that mode of income provision may be associated with successful ageing and its three dimensions, since a majority of respondents receiving regular income attained the three dimensions of successful ageing regardless of age group category. Likewise, there is an association between living above or below US $\$ 1.25$ per day with wellbeing and social engagement both at $\mathrm{p}<.05$. Overall, financial status is significantly associated with successful ageing as well as with wellbeing and social engagement. Respondents who are living above US $\$ 1.25$ per day have significantly higher scores in the attainment of wellbeing and social engagement. Qualitative findings suggest that the majority of older persons who identified overcoming hardship and poverty as part of their life experiences identified resiliency which may contribute to their positive outlook and understanding of successful ageing. Poverty and hunger have a significant effect on life expectancy as well as on the attainment of successful ageing in the Philippines. Limited coverage of the social pension contributes to the rising incidence of poverty and hunger among older Filipino persons. This study found that financial insecurity in old age hinder attainment of successful ageing, and they are attributed to the disadvantages experienced by older persons living in poor communities. Financial insecurity and health problems are attributed to the lack of universal social pensions and limited access to social welfare and health services in poor communities in the Philippines. Regular provision of financial support to older persons contributes to financial security in old age which is an important factor in successful ageing. Financial security in old age contributes to social engagement and in pursuing new activities among older Filipino persons. Therefore, government's social protection and social welfare program may prioritise older Filipino persons without pensions and financial support from family. Lastly, research on successful ageing may guide the development of comprehensive social welfare and health program in the Philippines that may serve as a reference for other developing countries.

Keywords: Social pension; Successful ageing; Mixed method; Poor older person; Poverty; Income classification; Living above or below US\$1.25; Wellbeing; Social interaction; Social engagement

\section{Introduction}

\section{Understanding successful ageing}

Understanding of the dimensions and associated factors that contribute to successful ageing is still evolving. To date, there is no universal consensus on the dimensions and associated factors of successful ageing [1-4]. Meanwhile, the most common dimension used in most studies on successful ageing is by Rowe and Kahn [1-5]. Among these, [6] identify Rowe and Kahn's three dimensions of successful ageing: physical functioning, wellbeing, and social engagement which have been adopted by most quantitative studies on successful ageing. 
The distinct sociocultural influences and perspective of older persons living in poor communities in the Philippines can contribute in broadening the understanding of successful ageing. One of the main challenges in the Philippines is poverty, followed by communicable and non-communicable diseases, and limited government funding for health and welfare services for older Filipino persons. In addressing these challenges, the Philippines enacted policies as early as 1992 to guide the implementation of social welfare programs for older persons. While the Philippine Government has made great strides with the enactment of policies for older persons, there is still a lack of research that explores the ageing process of older Filipino persons in their unique sociocultural environment.

\section{Successful ageing as a policy framework}

The concept of successful ageing has been used by governments in South Australia, the United States, Taiwan, and the United Kingdom as one of the bases for developing programs for older persons as well as by researchers for longitudinal studies $[2,7,8]$. For example, the findings from empirical studies on successful ageing have been utilized in different countries like Australia, the United States and Canada to inform their social welfare policies and programs and in exploring the challenges and opportunities brought about by an ageing population $[9,7,10]$. In the Philippines, there is an unprecedented increase in the number of persons aged 60 years and above. According to [11], demographic changes can be seen as both a positive development and a challenge especially for developing countries. For example, significant numbers of older Filipino persons remain in poverty, given the limited coverage of the old age pension and the threat of double burden of disease. Given the lack of research on successful ageing with economically poor older persons [6], argue that a more inclusive study on successful ageing needs to include older persons living in developing countries. Therefore, social pensions and increasing income level of older persons have been important strategy toward promoting of successful ageing.

\section{Successful ageing: social pensions}

According to Park (2009), there is an absence of comprehensive social security and a basic safety net, since only $9 \%$ to $30 \%$ of the older population receive non-contributory social pensions in the world. Social pensions for indigent older persons in the Philippines provide monthly cash transfers amounting to US\$12 dollars per month. Social pension for older persons is now becoming an important social welfare program and a social safety net to address poverty in old age. In the Philippines, social pension for indigent older persons is the main social welfare program to address poverty and hunger among poor older persons. The study by [12] in Thailand found that access to social pensions is influenced by gender and living arrangements.

They identified that female older persons who are single are in most need of government financial assistance. According to Park 2009 , there is an absence of comprehensive social security and a basic safety net, since only $9 \%$ to $30 \%$ of the older population receive non-contributory social pensions in the world. Social pensions for indigent older persons in the Philippines provide monthly cash transfers amounting to US\$12 dollars per month. Non-contributory social pension is becoming an important social safety net program in developing countries like the Philippines. Since there is limited study that explored the association of social pensions with successful ageing, it is important to explore whether there is an association between older Filipino persons receiving or not receiving social pension with the attainment of successful ageing and its key dimensions in the present study.

\section{Successful ageing: mode of income (living above or below US\$1.25 per day)}

Economic status of older persons significantly contributes to wellbeing, physical functioning, and social engagement of older persons in developed countries like Korea, Taiwan, Australia, and the United States [1,8]; [13-17]. Suggests that having adequate income is a key factor in the attainment of successful ageing. The study by [18] utilizing a representative random sample of 1,825 persons aged 65 years or older in Seoul, Korea, found that household and personal income were significantly associated with successful ageing. The international poverty line is US $\$ 1.25$ per day to measure whether a person is living above or below poverty [19]. Therefore, it is important to explore whether there is an association between older Filipino persons living above or below US\$1.25 per day with the attainment of successful ageing and its key dimensions in the present study. Since income determined the economic status of older Filipino persons, this article will explore the associations of social pensions and income of respondents with successful ageing and its three dimensions. Another example is the study of [12] in Thailand, which identified gender disadvantages such as lower income of older female persons and suggested the importance of prioritizing older female persons in social welfare programs like non-contributory social pensions. Therefore, this article will explain the association of social pensions and income with the attainment of successful ageing and its key dimensions namely wellbeing, physical functioning and social engagement.

\section{Research objective}

To explore the understanding and association between receiving social pension and level of income with the attainment of successful ageing, and how social pensions and income contributes to successful ageing in the Philippines.

\section{Methodology}

This study utilizes explanatory mixed method design. The study was divided into two parts: Study 1 explored the association between social pensions, and income with successful ageing. Successful ageing was measured using Rowe and Kahn's three dimensions of successful ageing namely wellbeing, physical functioning, and social engagement. The three dimensions were assessed through the following scale: World Health Office (WHO) Wellbeing scale, DUKE Social Support and Social Interaction scale, and KATZ Independence of Activities of Daily Living scale. Data for Study 1 were collected from 200 respondents between the ages of 65 and 93 living in poor rural and urban communities in the Philippines, using a structured 
questionnaire. Study 2 explored social pensioners experiences of successful ageing and how they used their pensions. Data for Study 2 were collected through in-depth interviews with 75 participants who were selected from Study 1. NVivo 10 software was utilized in the over-all project management as well as in analyzing both qualitative and quantitative data, and with SPSS 20 in exploring the significant associations.

\section{Independent, dependent variables and corresponding scales}

The sociodemographic variables: mode of income provision, receiving or not receiving social pension, and living above or below US\$1.25 per day. The dependent variables in this study consisted of the three dimensions of successful ageing: wellbeing, physical functioning and social engagement. Each of the three dimensions was measured by a corresponding scale. Wellbeing was measured using the five-item WHO Subjective Wellbeing scale. An example item included "I have felt cheerful and in good spirits". Responses were measured on a $0-5$ Likert ranging from $0=$ at no time to $5=$ all of the time. Physical functioning was measured using the sixitem Katz IADL Scale which measured either dependence or independence in activities of daily living such as bathing, dressing, and toileting. Social engagement was measured using the Duke Social Support and Social Interaction (DSSI) Scale. The DSSI scale consists of 10 questions measuring subjective social interaction. Responses to question 1 were measured on a three-point Likert scale, responses to questions 2-4 were measured on an eight-point Likert scale, and responses to questions 5-10 were measured on a three-point Likert scale. These scales were adopted because of their proven reliability in the literature. The following section provides a detailed explanation and method of computation for each scale.

\section{Sample}

The total sample for analysis was 200 respondents. The majority of the respondents were females at $57 \%(n=114)$, and $43 \%(n=86)$ were males. The respondents' ages ranged between 65 and 93 years old $(\mathrm{M}=72.93$ years old, $\mathrm{SD}=6.11$ years $)$. The mean estimated daily income was Php65.71 (SD = 119.34) while the median was Php27. The majority of the respondents were living below Php55 per day while $35.5 \%$ of the total respondents had no income. In this study, the majority of the respondents were living in poverty or below Php27 per day.

\section{Findings}

\section{Quantitative findings}

Social pensions and successful ageing: The majority, $91.5 \%$ ( $n=183$ ) of the total survey respondents, were not receiving social pensions, and among them, 53\% ( $\mathrm{n}=97$ ) were successful in attaining the three dimensions of successful ageing, while $47 \%$ $(\mathrm{n}=86)$ were not. Among respondents who were receiving social pensions, $8.5 \%(n=17), 41.2 \%(n=7)$ were successful in attaining the three dimensions of successful ageing, while $58.8 \%(n=10)$ were not. An age-stratified analysis revealed that a majority of old-old to oldest-old respondents who received social pensions $(60 \%)$ and did not receive social pensions (62.1\%) did not attain the three dimensions of successful ageing. In a cross-tabulation per total respondents and per stratified age group category with the attainment and non-attainment of successful ageing. Of the total $\mathrm{N}=200$ respondents, the majority were not in receipt of non-contributory social pensions from the Philippine Government $(91.5 \%, \mathrm{n}=183)$, were contributing in activities of OPO $(44 \%, \mathrm{n}=$ $88)$, and were living below US $\$ 1.25$ per day $(68.5 \%, n=137)$.

The Chi square revealed that there were no associations between social pension and successful ageing X2 (1) = .872, $p=.35$ per total survey respondents. To further explore the associations of social pension with the attainment of the three continuous scales that represent the dimensions of successful ageing, an independent sample t-test was performed. In the attainment of wellbeing, the t-test revealed that there was no significant difference between respondents with social pensions $(\mathrm{M}=56.12, \mathrm{SD}=11.76)$ and those without social pensions $(\mathrm{M}=58.19, \mathrm{SD}=20.54), \mathrm{t}(20)=-.41, \mathrm{p}=.68$. In the attainment of physical functioning, there was no significant difference between respondents with social pensions $(M=5.88$, $\mathrm{SD}=.33)$ and without social pensions ( $\mathrm{M}=5.81, \mathrm{SD}=.65), \mathrm{t}(20)=$ $.42, \mathrm{p}=.67$. In the attainment of social engagement, there was no significant difference between respondents with social pensions $(M$ $=20.94, \mathrm{SD}=4.23$ ) and without social pensions ( $\mathrm{M}=22.82, \mathrm{SD}=4.43)$, $t(20)=-1.68, p=.10$. The findings suggest that social pensions may not be associated with successful ageing, since a majority of the respondents who received social pensions did not attain the three dimensions of successful ageing. Likewise, a majority of the oldold to oldest-old respondents who received social pensions did not attain the three dimensions of successful ageing.

\section{Descriptive statistics}

(Table 1-3)

Table 1: List of independent variables used and their categories.

\begin{tabular}{|l|c|c|c|}
\hline \multirow{2}{*}{ Independent Variables } & No. of Categories & Code in SPSS & Categories \\
\hline \multirow{3}{*}{ Mode of income provision } & 3 & 1 & With regular income \\
\cline { 2 - 4 } & & 2 & Without income \\
\cline { 2 - 4 } & & 3 & With seasonal income \\
\hline
\end{tabular}




\begin{tabular}{|c|c|c|c|}
\hline \multirow{2}{*}{ Estimated daily income } & 2 & 1 & Living below US\$1.25 \\
\cline { 2 - 4 } & & 2 & Living above US\$1.25 Php5.91 per day \\
\hline \multirow{2}{*}{ Social pensions } & 2 & 1 & Receiving social pension \\
\cline { 2 - 4 } & & 2 & Not receiving social pension \\
\hline
\end{tabular}

Table 2: Sociodemographic characteristics of the sample respondents.

\begin{tabular}{|c|c|c|c|}
\hline Variables & Category & Number (n) & Percent (\%) \\
\hline \multirow{3}{*}{ Income classification } & With regular income & 41 & 20.5 \\
\hline & Without income & 103 & 51.5 \\
\hline & With seasonal income. & 56 & 28 \\
\hline \multirow{2}{*}{$\begin{array}{l}\text { Earning below or } \\
\text { above US } \$ 1.25 \text { per day }\end{array}$} & Below US $\$ 1.25$ per day or Php55.91 per day & 120 & 60 \\
\hline & Above US $\$ 1.25$ per day or Php55.91 per day & 80 & 40 \\
\hline \multirow{2}{*}{ Social Pensions } & Receiving Social Pension & 17 & 8.5 \\
\hline & Not receiving Social Pension & 183 & 91.5 \\
\hline
\end{tabular}

Table 3: P-value of sociodemographic variables by age category and per total respondents with two dichotomous variables using chi square test of independence.

\begin{tabular}{|c|c|c|c|}
\hline Variables & $\begin{array}{c}\text { Young-old to Middle-old } \\
\mathbf{6 5 - 7 4} \text { years old) P-value }\end{array}$ & $\begin{array}{c}\text { Old-old to Oldest-old (75 } \\
\text { years and over) P-Value }\end{array}$ & $\begin{array}{c}\text { Total Respondents n(\%) } \\
\text { P-value }\end{array}$ \\
\hline Income classification & $.01^{* *}$ & $.01^{* *}$ & $.01^{* * *}$ \\
\hline Social Pensions & 0.78 & 0.88 & 0.35 \\
\hline $\begin{array}{c}\text { Income level (Living below or above } \\
\text { US } \$ 1.25 \text { dollar per day) }\end{array}$ & 0.06 & 0.58 & $.01^{* *}$ \\
\hline
\end{tabular}

Note. ${ }^{*} \mathrm{p}<.05 .{ }^{* *} \mathrm{p}<.01 .{ }^{* * *} \mathrm{p}<.001$. Dichotomous variables $=$ attainment or non-attainment of the three dimensions of successful ageing.

\section{Modes of income provision}

The majority $51.5 \%(n=103)$ of the total respondents did not have an income, and among them, 40.8\% ( $n=42)$ were successful in attaining the three dimensions of successful ageing while $69.2 \%$ ( $n=61$ ) were not. The second largest group of respondents were those with seasonal income comprising $28 \%(n=56)$ of the total respondents, and among them, 50\% ( $n=28)$ were successful in attaining the three dimensions of successful ageing while 50\% (n $=28$ ) were not. The third group of respondents were those with regular income, $20.5 \%(\mathrm{n}=41)$ of the total respondents, and among them, $82.9 \%(n=34)$ were successful in attaining the three dimensions of successful ageing while $17.1 \%(n=7)$ were not. An age-stratified analysis revealed that the majority of respondents with regular income (82.2\%) and with seasonal income $(57.5 \%)$ attained the three dimensions of successful ageing. Among oldold to oldest-old respondents, only those with regular income $(83.3 \%)$ attained the three dimensions of successful ageing. The findings suggest that mode of income provision may be associated with successful ageing and its three dimensions, since a majority of respondents receiving regular income attained the three dimensions of successful ageing regardless of age group category.

The Chi square revealed that there is an association between mode of income with successful ageing $\chi^{2}(2)=20.99, p<.001$ per total respondents. To further explore the significant differences with mode of income provision for respondents with the attainment of three continuous scales that represent the dimensions of successful ageing, analysis of variance (ANOVA) tests were performed, as shown in Table 4. In the attainment of wellbeing, there were significant difference with mode of income of respondents, $F$ $(2,20)=28.54, p<.001, \eta^{2}=.23$. In the attainment of physical functioning, there was a significant difference in mode of income of the respondents, $F(2,20)=1.40, p=.248, \eta^{2}=.01$. In the attainment of social engagement, there was a significant difference in mode of income of the respondents, $F(2,20)=14.59, \mathrm{p}<.001, \eta^{2}=.12$. To further explore the significant differences in mode of income with wellbeing and social engagement, ANOVA LSD post-hoc tests were performed. As seen in Table 4, respondents with regular income have significantly higher scores with the attainment of wellbeing and social engagement compared to those without income and with seasonal income at $\mathrm{p}<.01$. 
Table 4: P-value of Mode of Income for each Dimension of Successful Ageing (SA) using ANOVA.

\begin{tabular}{|c|c|c|c|c|c|c|}
\hline $\begin{array}{c}\text { Dimensions of SA } \\
\text { (Scale) }\end{array}$ & Sum of Squares & $\mathrm{df}_{1}\left(\mathrm{df}_{2}\right)$ & Mean Square & $\mathbf{F}$ & Sig. & $\eta^{2}$ \\
\hline Wellbeing (WHO Wellbeing) & 17.31 & $2(20)$ & 88.16 & 28.54 & $.01^{* * *}$ & 0.23 \\
\hline Physical Functioning (Katz IADL) & 1.12 & $2(20)$ & 0.56 & 1.4 & 0.25 & 0.01 \\
\hline Social Engagement (DSSI) & 50.88 & $2(20)$ & 25.44 & 14.59 & $.01^{* * *}$ & 0.12 \\
\hline
\end{tabular}

Note. ${ }^{*} \mathrm{p}<.05 .{ }^{* *} \mathrm{p}<.01 .{ }^{* * *} \mathrm{p}<.001 . \mathrm{WHO}=$ World Health Organization. IADL $=$ Independence in Activities of Daily Living. DSSI $=$ Duke Social Support and Social Interaction.

\section{Living below or above us $\$ 1.25$ a day and successful ageing}

The majority, $68.5 \%(\mathrm{n}=137)$ of the total respondents were living below US $\$ 1.25$ per day, and $44.5 \%(n=61)$ of these were successful in attaining the three dimensions of successful ageing namely wellbeing, physical functioning, and social engagement while $55.5 \%(n=76)$ were not. Among respondents living above US $\$ 1.25$ per day, 31.5\% ( $n=63), 68.3 \%(n=43)$ were successful in attaining the three dimensions of successful ageing while $31.7 \%$ ( $n=20$ ) were not. An age-stratified analysis revealed that the majority of the respondents who were living above US\$1.25 per day $(70 \%)$ and living below US\$1.25 per day (53.2\%) attained the three dimensions of successful ageing among young-old to middleold respondents. Meanwhile, the majority of old-old to oldestold respondents who were living above US $\$ 1.25$ per day (61.5\%) attained the three dimensions of successful ageing, while the majority of respondents living below US $\$ 1.25$ per day (66.7\%) did not attain the three dimensions of successful ageing. The findings suggest that income level may be associated with successful ageing, since the majority of respondents who were living above US $\$ 1.25$ per day attained the three dimensions of successful ageing. Likewise, the majority of respondents who were living above and below US $\$ 1.25$ per day attained the three dimensions of successful ageing, while a majority of respondents living below US $\$ 1.25$ per day did not attain the three dimensions of successful ageing in both age group categories.

The Chi square revealed that there were associations between living above US $\$ 1.25$ per day and successful ageing $\chi^{2}(1)=9.74$, $\mathrm{p}<.05$ per total respondents. To further explore the associations of living above or below US\$1.25 per day with the attainment of three continuous scales that represent the dimensions of successful ageing, an independent sample t-test was performed, as shown in Table 4. In the attainment of wellbeing, there was a significant difference between respondents living above US\$1.25 per day ( $\mathrm{M}=66.33, \mathrm{SD}=22.19$ ) and living below US $\$ 1.25$ per day ( $\mathrm{M}$ $=54.18, \mathrm{SD}=17.61), \mathrm{t}(20)=-4.17, \mathrm{p}<.01$. In the attainment of physical functioning, there was no significant difference between respondents living above US $\$ 1.25$ per day $(\mathrm{M}=5.92, \mathrm{SD}=.27)$ and living below US $\$ 1.25$ per day $(\mathrm{M}=5.77, \mathrm{SD}=.74) \mathrm{t}(20)=-1.53, \mathrm{p}=$ .13. In the attainment of social engagement, there was a significant difference between respondents living above US $\$ 1.25$ per day $(\mathrm{M}=$ $24.59, \mathrm{SD}=4.09)$ and living below US $\$ 1.25$ per day $(\mathrm{M}=21.77, \mathrm{SD}$ $=4.32), \mathrm{t}(20)=-4.35, \mathrm{p}<.05$.

Table 5: P-value of living above or below US\$1.25 for each dimension of Successful Ageing (SA) using independent samples t- test.

\begin{tabular}{|c|c|c|c|c|c|c|}
\hline \multicolumn{1}{|c|}{$\begin{array}{c}\text { Dimensions of SA } \\
\text { (Scale) }\end{array}$} & $\mathbf{F}$ & Sig. & $\mathbf{t}$ & $\mathbf{D f}$ & Living above US\$1.25 per day & Living below US\$1.25 per day \\
\hline Wellbeing (WHO Wellbeing) & .30 & $.01^{* *}$ & 4.17 & 20 & $66.33(22.19)$ & $54.18(17.61)$ \\
\hline Physical Functioning (Katz IADL) & .12 & 0.13 & 1.53 & 20 & $5.92(.27)$ & $5.77(.74)$ \\
\hline Social Engagement (DSSI) & 19 & $.05^{*}$ & 4.35 & 20 & $24.59(4.09)$ & $21.77(4.32)$ \\
\hline
\end{tabular}

Note. ${ }^{*} \mathrm{p}<.05 .{ }^{* *} \mathrm{p}<.01 .{ }^{* *} \mathrm{p}<.001$. WHO $=$ World Health Organization. IADL $=$ Independence in Activities of Daily Living. DSSI $=$ Duke Social Support and Social Interaction.

Table 5 presents the findings of a stratified analysis using independent sample t-test between respondents living above US $\$ 1.25$ per day and living below US $\$ 1.25$ per day. There is an association of living above or below US $\$ 1.25$ per day with wellbeing at $\mathrm{p}<.05$ and social engagement at $\mathrm{p}<.01$ among young-old and middle-old respondents. Likewise, there is an association between living above or below US $\$ 1.25$ per day with wellbeing and social engagement both at $\mathrm{p}<.05$. Overall, financial status is significantly associated with successful ageing as well as with wellbeing and social engagement. Respondents who are living above US $\$ 1.25$ per 
day have significantly higher scores in the attainment of wellbeing and social engagement.

\section{Qualitative findings}

The qualitative findings suggest that social pensions and assistance from government is one of the facilitating factors in the attainment of successful ageing, which was mentioned by 16 interview participants. Assistance from government is explained as receiving social pensions and DSWD assistance. According to the key informants, social pension contributes to the daily basic needs of older persons and they were very appreciative of the pension they received from the government. Interview participants with income placed importance on being healthy as the main theme of successful ageing, based on a statement below from an 80-year-old female participant. Meanwhile, interview participants who were not receiving an income placed importance on living longer as their understanding of successful ageing. In the Philippine context, income is important to remain healthy, and the government passed a law in 2014 to provide universal health care for older Filipino persons who are not receiving any income or pension and those whose health care costs are not covered by their employed children. "Yes, of course, successful, because at this age I am still healthy, my family can still rely on me. It's to have good relationship with others, don't do anything bad to them, that is what I always pray for, that even though I'm poor, as long as I don't get sick, as long as I have good health I'm happy." (80 year old, Female) Another hindering factor is financial insecurity which was mentioned by eight interview participants. Financial insecurity is explained as a lack of pension and having no regular income which may make older persons fully dependent on their family for financial support for their daily basic needs. Likewise, financial insecurity is not receiving old age pension. A 70-year-old female participant mentioned that love and care from the children is more important than financial security in old age. Even though I don't have financial security I can still survive the day and I feel loved by my children and grandchildren and I know I am loved by my family it's a good feeling.

(70 year old, Female) Moreover, experiencing a disaster also contributes to financial insecurity in old age due to loss of livelihood based on the statement of a 73-year-old participant: It helps because we don't have any other source of livelihood, also I'm grateful that it wasn't damaged/consumed by the fire, if that was burned, we're done for. Nothing more for us, I'm even teary eyed. (73 year old, Female) A 69 year-old female participant living in a rural community mentioned that despite poverty and hardship people view themselves as successful because they have unity and are helping each other in their communities. The findings suggest that even older persons who have no income or are living below poverty can still be successful in old age, which they attribute to having a sense of dignity, interpreted as being able to help others who are more in need. "Those who live here, the tribe here is different, here even if we have none, we're still successful, if we go through hardships it's just fine. They're the same, what's different is the objective of the things that we do, the things we do here in the tribe, like the things we do here and the things they do there are different, the work and livelihood are different here compared to theirs below". (69 year old, Female) A 67-year-old male participant mentioned that he would not like his children to experience the hardship he had been through. Older persons would want to improve the economic condition of their children and they want to instill in their family the importance of hard work and determination and they want their life experiences to serve as an inspiration for others: It's that I grew up in poverty, I grew up in the province, I already got to realise that that when I grow old I won't let my children experience what I felt, that is why I never obliged them to do anything, I don't even ask them to carry things around that is why even though they are old they still love me. (67 year old, Male) Life experiences is resilience which is described as being able to strive and survive in spite of hardship and to succeed in life, based on the statement below from an 82-year-old male participant. The majority of older persons who identified overcoming hardship and poverty as part of their life experiences identified resiliency which may contribute to their positive outlook and understanding of successful ageing.

\section{Conclusion}

\section{Poverty and hunger}

Poverty and hunger have a significant effect on life expectancy as well as on the attainment of successful ageing in the Philippines. In analyzing income level as a determinant of poverty, the [20] has suggested that an individual needs to have an income of US\$1.25 per day to live above the poverty level. In a report, $21 \%$ of people in developing countries were living below US $\$ 1.25$ per day and were considered poor. In the Philippines, an individual needs 974 Philippine pesos ( $\mathrm{Php}$ ) to meet the monthly food requirement; and Php1,403 to stay out of poverty, while a Filipino family of five requires a monthly income of $\mathrm{Php} 7,017$ to live above poverty $[20,21]$. According to [22], if a household in the Philippines is classified as indigent, then all members of the household are counted as indigent. In a [23] report, $23 \%$ of the total population of 94.9 million Filipinos, or 21.83 million people, were living below US $\$ 1.25$ per day or in poverty. Given the widespread poverty in the Philippines, Park (2009) argues that poverty among older persons is widespread, since large numbers of the lifetime poor will never benefit from pension systems. Limited coverage of the social pension contributes to the rising incidence of poverty and hunger among older Filipino persons. Poverty is the most substantial issue in the Philippines, given the average $32.9 \%$ incidence. In 2009, the number of poor older persons was estimated at 1,297,159 [22]. In the [24], 55\% of the families subjectively rated themselves as poor. In comparing poverty incidence in rural and urban settings in the Philippines, the highest incidence of poverty among older persons was registered at $46.5 \%$ in a rural community, while the lowest rate was at $4.4 \%$ in an urban community [22].

\section{Financial support and successful ageing}

This study found that regular provision of financial support to older persons contributes to financial security in old age which is 
an important factor in successful ageing. According to [17], income security in old age provides better health care and greater ability to maintain previous activities or pursue new ones. Financial security in old age contributes to social engagement and in pursuing new activities among older Filipino persons. This study supports the findings that having adequate income for older persons is an important factor in the attainment of successful ageing [18];[25]. Respondents with no income and with seasonal income have significantly lower scores in wellbeing and social engagement and are less likely to be successful in old age regardless of age group category. Therefore, government's social protection and social welfare program may prioritise older Filipino persons without pensions and financial support from family.

\section{Comprehensive social welfare for poor older Filipino persons}

Social work can make a distinctive contribution in addressing the multidimensional needs of older persons especially those who are most vulnerable [25]. This study found that financial insecurity in old age hinder attainment of successful ageing, and they are attributed to the disadvantages experienced by older persons living in poor communities. Financial insecurity and health problems are attributed to the lack of universal social pensions and limited access to social welfare and health services in poor communities in the Philippines. One of the highlights of the social welfare policy and program in the Philippines is the implementation of social pensions for selected indigent older persons, which is intended to address the rising incidence of poverty and hunger. This study found that respondents who are living below US\$1.25 per day are from rural communities and dependent on their family or neighbours for their daily subsistence. Poor older Filipino persons are living on the edge, in poor housing conditions, and in disaster-prone communities, and the majority have minimal participation in decision making [22]; [26]. According to Help Age International (2011), a universal social pension or means-tested old age pension can be adopted to address poverty in developing countries.

Meanwhile, this study found that receiving regular pension or financial support from family contributes to the attainment of successful ageing as well as to the wellbeing and social engagement of the survey respondents. The financial support to older persons is attributed to generativity theory, which is the mutual support between older persons and younger working members of the family. Moreover, generativity theory explains the importance of mutual support as well as the importance of older persons' contributing to their family and community, which may contribute to the positive outlook of older persons. Likewise, survey respondents living above US\$1.25 per day have significantly higher scores in wellbeing and social engagement, compared to respondents living below US $\$ 1.25$ per day, regardless of age category. Living above poverty among older Filipino persons is an important factor that may contribute to successful ageing. This study also finds that social pensions do not contribute to the attainment of successful ageing and its dimensions, since social pensioners only receive less than \$12 dollar a month.

\section{Recommendations}

Older persons living in poverty or below US $\$ 1.25$ a day may be prioritized in social protection programs such as social pensions and government cash transfer programs, and that community support for promoting social engagement may be developed through OPOs. Financial insecurity in old age may be addressed by promoting a universal social pension in the Philippines that will provide US $\$ 1.25$ per day to indigent older persons. There may be a need to explore increasing coverage of social pensions for indigent older Filipino persons to include those who are 60 years old and above. Further research on the hindering factors, as well as the facilitating, is needed to inform social work interventions and social welfare policy and programs for older Filipino persons. Social pensions were not associated with wellbeing, physical functioning and social engagement among respondents. Likewise, recipients of social pensions had a lower subjective perspective on their personal health and a negative outlook in life, since they had been considered as the most vulnerable among their age group category. Interview participants who were receiving social pensions revealed that the non-contributory pensions from the government supplemented their daily needs in buying food and medicines, and they were also sharing with their families and grandchildren. This study suggests that social pensions for indigent older persons may need to be increased to contribute to the attainment of successful ageing and its dimensions. Respondents from rural communities were more disadvantaged in the attainment of wellbeing and social engagement and a majority are living below US\$1.25 per day or without income. Rural social work needs development given the different dynamics of rural life as well as the limited research on rural social work $[27,28]$. Suggests the need for enhancing social work rural practice through research on older persons. According to [29], social workers who work with ageing people need to be aware of rural-urban differences and focus on clients' social support systems. Integrating rural social work practice in the Philippines may contribute in promoting attainment of successful ageing in the poor rural communities in the Philippines. Responsive social welfare policy and program are important in creating equal opportunities for rich and poor older Filipino persons to age successfully. This study may be utilized in the development of a means-test to identify the beneficiaries of social welfare program for poor older Filipino persons. Moreover, this study supports the [28] recommendations that social welfare policy and program need to shift focus onto eradication of poverty especially among older persons. Social workers may advocate for the improvement of social welfare policy and programs for poor older Filipino persons. For example, social workers may advocate to Department of Social Welfare and Development (DSWD) to increase the amount of social pension to US\$1.25 per day.

Likewise, DSWD may enhance its social welfare program to strengthen family and community to provide social protection to poor older Filipino persons. This study found that social pensions provided by DSWD do not significantly contribute to the attainment of successful ageing in the Philippines, since it only provides US\$12 per month. In the Philippines, the coverage of 
government and private pension system or contributory pensions among older persons is very low, due to large informal sector and high poverty incidence [30]. [26] estimates that $21 \%$ of older persons in developing countries are living below US $\$ 1.25$ per day or living in poverty. Older persons living in poverty have limited access to healthcare, electricity, safe water and pension (Help Age International 2011; [31-43]. Lastly, research on successful ageing may guide the development of comprehensive social welfare and health program in the Philippines that may serve as a reference for other developing countries.

\section{References}

1. Bowling A (2007) Aspirations for older age in the $21^{\text {st }}$ Century: What is successful aging? The International Journal of Aging and Human Development 64(3): 263-297.

2. Bowling A, Iliffe S (2006) Which model of successful ageing should be used? Baseline findings from a British longitudinal survey of ageing. Age and Ageing 35(6): 607-614.

3. Knight T, Ricciardelli L (2004) Factors associated with successful ageing. Paper presented at the ERA 2004: Contributing to an ageing agenda: abstracts and proceedings. The $3^{\text {rd }}$ National Conference for Emerging Researchers in Ageing, $2^{\text {nd }}$ December 2004 Brisbane Convention and Exhibition Centre.

4. Tate RB, Lah L, Cuddy TE (2003) Definition of successful aging by elderly Canadian males: The Manitoba follow-up study. Gerontologist 43(5): 735-744.

5. Peel N, Bartlett H, McClure R (2004) Healthy ageing: How is it defined and measured? Australasian Journal on Ageing 23(3): 115-119.

6. Depp CA, Jeste DV (2006) Definitions and predictors of successful aging: a comprehensive review of larger quantitative studies. American Journal of Geriatric Psych 14(1): 6-20.

7. Andrews Clark M, Luszcz M (2002) Successful aging in the Australian longitudinal study of aging: Applying the MacArthur model crossnationally. Journal of Social Issues 58(4): 749-765.

8. Hsu HC (2005) Gender disparity of successful aging in Taiwan. Women \& health 42(1): 1-21.

9. American Association of Retired Persons (2012) Best cities for successful ageing.

10. Roos NP, Havens B (1991) Predictors of successful aging: a twelve-year study of Manitoba elderly. American Journal of Public Health 81(1): 6368.

11. Harper S, Leeson G (2008) Introduction. Journal of Population Ageing 1: $1-5$.

12. Knodel J, Chayovan N (2008) Gender and ageing in Thailand: A situation analysis of older women and men. Population Studies Center Report 08664. University of Michigan, USA.

13. Jang SN, Choi YJ, Kim DH (2009) Association of socioeconomic status with successful ageing: Differences in the components of successful ageing: Journal of Biosocial Science 41(2): 207-219.

14. Jorm AF, Christensen H, Henderson AS, Jacomb PA, Korten AE, et al. (1998) Factors associated with successful ageing. Australasian Journal on Ageing 17(1): 33-37.

15. Lamb VL, Myers GC (1999) A comparative study of successful aging in three Asian countries. Population Research and Policy Review 18(5): 433-450.

16. Li C, Wu W, Jin H, Zhang X, Xue H, et al. (2006) Successful aging in Shanghai, China: definition, distribution and related factors. International Psychogeriatrics 18(3): 551-563.

17. Reichstadt J, Depp C, Palinkas L, Folsom DP, Jeste DV (2007) Building blocks of successful aging: a focus group study of older adults' perceived contributors to successful aging. American Journal of Geriatric Psychiatry 15(3): 194-201.

18. Holmes J (2006) Successful Ageing: A Critical Analysis. (Doctor of Philosophy), Massey University, Palmerston North, New Zealand.

19. United Nations (2013) Indicators for monitoring the millennium development goals. Proportion of population living below $\$ 1.25$ per day.

20. World Bank (2014) Poverty overview, Washington, USA.

21. National Statistical Coordination Board (2011) Highlights of the 2009 official poverty statistics.

22. Castro LV (2009) Poverty statistics for the basic sectors. Paper presented at the Users' Forum on the 2006 Poverty Statistics for the Basic Sectors and 2006 Child Development Index, Manila.

23. United Nations Population Division (2011) World population prospects: The 2010 revision. Statistical yearbook for Asia and the Pacific 2011.

24. Social Weather Stations (2014) Fourth Quarter 2013 Social Weather Survey.

25. Ray M, Milne A, Beech C, Phillips JE, Richards S, et al. (2015) Gerontological social work: reflections on its role, purpose and value. The British Journal of Social Work 45(4): 1296-1312.

26. Help Age International (2012) Older people in emergencies-identifying and reducing risks.

27. Agbim K, Ozanne E (2007) Social work educators in a changing higher education context: Looking back and looking forward 1982-2005. Australian Social Work 60(1): 68-82.

28. International Federation of Social Workers (2009) International policy on ageing and older adults.

29. Evans RJ (2009) A comparison of rural and urban older adults in Iowa on specific markers of successful aging. Journal of Gerontological Social Work 52(4): 423-438.

30. Mesa-Lago C, Viajar V, Castillo R (2011) Pensions in the Philippines: Challenges and Ways Forward.

31. United Nations (2012) Population ageing and development: Population Division, New York, USA.

32. (2009) Act No 9257, An act granting additional benefits and privileges to senior citizens amending for the purpose republic Act 7432.

33. Bowling A, Dieppe P (2005) What is successful ageing and who should define it?. British Medical Journal 331(7531): 1548-1551.

34. Department of Social Welfare and Development (2011) DSWD to implement social pension for seniors.

35. Department of Social Welfare and Development (2012) DSWD Annual Report 2012. Quezon City, Philippines

36. Help Age International (2010) Health policy.

37. Koenig HG, Westlund RE, George LK, Hughes DC, Blazer DG, et al. (1993) Abbreviating the duke social support index for use in chronically ill elderly individuals. Psychosomatics 34(1): 61-69.

38. National Statistics Office (2005) Senior citizens comprised six percent of the population (151). Manila, Philippines.

39. Powers JR, Goodger B, Byles JE (2004) Assessment of the abbreviated Duke Social Support Index in a cohort of older Australian women. Australasian Journal on Ageing 23(2): 71-76. 
40. Psykiatrisk Center Nordsjælland (2014) About the WHO-5.

41. United Nations (2011) Madrid international plan of action on ageing.

42. Zacher H (2015) Successful aging at work. Work, Aging and Retirement 1(1): 4-25.
43. Reichstadt J, Sengupta G, Depp CA, Palinkas LA, Jeste DV (2010) Older adults' perspectives on successful aging: Qualitative interviews. American Journal of Geriatric Psych 18(7): 567-575.

For possible submissions Click below: 